\title{
Highly Sensitive Humidity Sensors Based on Polyethylene Oxide/CuO/Multi Walled Carbon Nanotubes Composite Nanofibers
}

\author{
Waqas Ahmad ${ }^{1}{ }^{(D,}$, Bushra Jabbar ${ }^{1}$, Imtiaz Ahmad ${ }^{1}$, Badrul Mohamed Jan ${ }^{2}$, Minas M. Stylianakis ${ }^{3}(\mathbb{D}$, \\ George Kenanakis ${ }^{3}$ and Rabia Ikram ${ }^{2, *}$ \\ 1 Institute of Chemical Sciences, University of Peshawar, Khyber Pukhtunkhwa 25120, Pakistan; \\ waqasahmad@uop.edu.pk (W.A.); bushrajabbar93@gmail.com (B.J.); dr_imtiaz@uop.edu.pk (I.A.) \\ 2 Department of Chemical Engineering, University of Malaya, Kuala Lumpur 50603, Malaysia; \\ badrules@um.edu.my \\ 3 Institute of Electronic Structure and Laser, Foundation for Research and Technology-Hellas, N. Plastira 100, \\ Vasilika Vouton, GR-700 13 Heraklion, Greece; stylianakis@iesl.forth.gr (M.M.S.); \\ gkenanak@iesl.forth.gr (G.K.) \\ * Correspondence: raab@um.edu.my
}

\section{check for} updates

Citation: Ahmad, W.; Jabbar, B.; Ahmad, I.; Mohamed Jan, B.; Stylianakis, M.M.; Kenanakis, G.; Ikram, R. Highly Sensitive Humidity Sensors Based on Polyethylene Oxide/CuO/Multi Walled Carbon Nanotubes Composite Nanofibers. Materials 2021, 14, 1037. https:// doi.org/10.3390/ma14041037

Academic Editor: Antonio Di Bartolomeo

Received: 18 January 2021

Accepted: 16 February 2021

Published: 22 February 2021

Publisher's Note: MDPI stays neutral with regard to jurisdictional claims in published maps and institutional affiliations.

Copyright: (c) 2021 by the authors. Licensee MDPI, Basel, Switzerland. This article is an open access article distributed under the terms and conditions of the Creative Commons Attribution (CC BY) license (https:/ / creativecommons.org/licenses/by/ $4.0 /)$.

\begin{abstract}
Polymer composites are favorite materials for sensing applications due to their low cost and easy fabrication. In the current study, composite nanofibers consisting of polyethylene oxide (PEO), oxidized multi-walled carbon nanotubes (MWCNT) and copper oxide $(\mathrm{CuO})$ nanoparticles with $1 \%$ and $3 \%$ of fillers (i.e., PEO-CuO-MWCNT: $1 \%$, and PEO-CuO-MWCNT: $3 \%$ ) were successfully developed through electrospinning for humidity sensing applications. The composite nanofibers were characterized by FTIR, XRD, SEM and EDX analysis. Firstly, they were loaded on an interdigitated electrode (IDE), and then the humidity sensing efficiency was investigated through a digital LCR meter (E4980) at different frequencies $(100 \mathrm{~Hz}-1 \mathrm{MHz})$, as well as the percentage of relative humidity (RH). The results indicated that the composite nanofibers containing $1 \%$ and $3 \%$ MWCNT, combined with $\mathrm{CuO}$ in $\mathrm{PEO}$ polymer matrix, showed potent resistive and capacitive response along with high sensitivity to humidity at room temperature in an $\mathrm{RH}$ range of 30-90\%. More specifically, the PEO-CuO-MWCNT: 1\% nanocomposite displayed a resistive rapid response time within $3 \mathrm{~s}$ and a long recovery time of $22 \mathrm{~s}$, while the PEO-CuO-MWCNT: $3 \%$ one exhibited $20 \mathrm{~s}$ and $11 \mathrm{~s}$ between the same RH range, respectively.
\end{abstract}

Keywords: polyethylene oxide; oxidized multi-walled carbon nanotubes; humidity sensors; copper oxide; composite nanofibers; electrospinning

\section{Introduction}

Recently, tremendous efforts have been made to improve the performance of chemical and physical sensors for technological and daily life applications [1]. In some areas of life, continuous humidity monitoring is essential. Therefore, humidity sensors significantly contribute to various sectors including agriculture, chemical and food production, climate control, environmental monitoring and health, as well as various industrial sectors such as electronics, paper, automobile and pharmaceuticals production [2]. The basic requirements towards the development of excellent and accurate humidity sensors are an exceptionally low hysteresis followed by negligible temperature effect, fast recovery times, thermal stability, long-term durability, resistance to pollutants, low cost and over a wide range sensitivity of $\mathrm{RH}$ [3]. A number of materials are used to fabricate humidity sensors such as ceramics, semiconductors and polymers; these sensors follow different mechanisms for measuring the humidity level, which include humidity sensing by change in resistance, capacitance, surface acoustic wave, optical fiber and quartz crystal microbalance [4]. Owing to economical and specific detection mechanisms, capacitive sensors are the most widely used [5]. 
The mechanism of resistance-dependent humidity sensors hinges on the impedance of the sensing layer, while the capacitive one depends on the dielectric constant.

Moreover, polymer-based humidity sensors offer high sensitivity, small hysteresis, power efficiency, flexibility, low cost and versatile applications. The performance of humidity sensors relies on the sensitivity of sensing materials, which is closely associated with their chemical structure and specific functions. Hence, the sensitivity enhancement of these sensing materials towards humidity is challenging [6]. Very recently, doping of nanomaterials such as metal oxides (i.e., $\mathrm{TiO}_{2}, \mathrm{ZnO}, \mathrm{SnO}_{2}, \mathrm{Al}_{2} \mathrm{O}_{3}, \mathrm{CuO}$ ) $[7,8]$, carbon-based materials (i.e., carbon nanotubes (CNTs) and graphene) [9] and hydrophilic polymers (i.e., polyethyleneimine (PEI) [10], polyethylene oxide (PEO) [11], polyvinyl alcohol (PVA) [12] and polyaniline (PANI) [13]) have been utilized as composite sensors to obtain an improved sensitivity and response time.

Over the years, the incorporation of inorganic nanomaterials into polymers has been extensively reported. Metals and metal oxide nanostructures have been paid much attention in the development of sensing devices due to their divergent physical and chemical properties [14]. Metal oxides are preferred over other materials because of their high chemical stability, broad operating temperature range and good mechanical strength [15]. In particular, $\mathrm{CuO}$, which is a p-type semiconducting material, with low bandgap energy $(1.2 \mathrm{eV})$ at ambient temperature, has received much attention. It has been found that $\mathrm{CuO}$ can be employed in supercapacitors, field emitters and storage media. Based on its efficient gas sensing and photoelectric properties, $\mathrm{CuO}$ is extensively deployed in the fabrication of sensors [16].

On other hand, CNTs have been applied for humidity sensing more widely compared to other carbon-based materials due to their superior electrical, physical and chemical properties. In addition, CNTs possess a large surface-to-volume ratio and nanoscale structure with a hollow core, and hence they are capable of adsorbing large amounts of foreign molecules on the surface [3]. Capacitive and resistive humidity sensors based on oxidized multi-walled carbon nanotubes (MWCNTs) have shown remarkable response and sensitivity, while the addition of CNTs as fillers have improved the electrical and mechanical properties of polymer matrix [9]. In previous studies, ceramics and polymer-based humidity sensors have been tested and compared [17]. Unlike ceramic-based humidity sensors, the polymer-based ones have shown high flexibility, very fast great response time and stability.

A significant variation of permittivity and conductivity among polymer-based humidity sensors can be improved by controlling the porosity and the sensing layer of the polymer matrix [18]. Thanks to their low-cost and easy fabrication, polymers have been extensively used as sensitive materials in different types of sensors [19]. Many studies have demonstrated that polymers can react to any change of humidity up to the micron level of diameter for various industrial applications. Moreover, the response of a polymer-based sensor depends on the analyte's diffusion into the sensing layer. It was reported that in the case of hydrophilic polymers, the diffusion coefficient of water is low because of the hydrogen bonding and solubility issues [20]; therefore, highly porous polymers with reduced hydrophilicity are being considered more for humidity sensing applications [21]. However, hydrophilic polymers can be used to fabricate high-sensitivity humidity sensors by crosslinking, grafting or by incorporation of a variety of fillers $[20,22,23]$. Very recently it has been reported that polymeric humidity sensors exhibited unique sensing properties by tuning their electrical characteristics, including the capacitance, at various humidity and conductivity levels as a function of the polymeric moisture content [5]. For instance, the active layer of polyethylene oxide (PEO) is a good candidate for humidity sensing because of the variation in conduction of its ion due to changing the RH [24]. In recent years, due to its toxicity-free nature, water solubility, biodegradability and biocompatibility, PEO has attracted attention for progress in humidity sensing. Therefore, the investigation of a unique sensing material and methods to fabricate high-performance sensors is highly desirable [25]. Compared to conventional methods, the electrospinning technique is a 
promising and economical method for one-dimensional nanofibers based on metal oxide nanostructures or polymer-based composites [26].

Recently, miniaturized sensors for portable devices such as mobile phones are available, including the following: SHTC1 humidity sensor from Sensirion and LPS331AP pressure sensor from STMicroelectronics are being used in Samsung cell phones; Bosch Sensortec company introduced a miniaturized humidity sensor capable of sensing pressure and temperature (BME280), which are based on Micro-Electro Mechanical Systems (MEMS) [27]. Although the power consumption for these sensors is very small because of their microsize, proportionally, their sensing capacity is also very small, leading to a high signal-to-noise ratio, which requires amplification; likewise, parametric amplification may also be required [28]. All these facts push forward the search for high sensitivity humidity sensors.

The present work demonstrates the realization of low-cost, efficient, flexible and highly stable humidity sensors based on polyethylene oxide, $\mathrm{CuO}$ and MWCNTs composite nanofibers by electrospinning. The morphology and structure of composite nanofibers were investigated by SEM, FTIR, EDX and XRD analysis. The humidity sensing performance of the prepared PEO-CuO-MWCNT composite nanofibers was studied through an LCR meter (Inductance, Capacitance and Resistance metre) at fluctuating frequency and $\mathrm{RH}$ conditions. The said sensors showed a high capacitive response to humidity, exhibiting high sensitivity, good linearity and fast recovery and response times. Thanks to these remarkable properties, the sensors can be advantageous in several applications such as the monitoring of health and medical facilities, environmental measurements, engineering instruments and remote control of various electronic devices.

\section{Materials and Methods}

\subsection{Chemicals and Reagents}

PEO powder (Merck KGaA; Darmstadt, Germany) with viscosity average molecular weight of 30,000 g/mol. and MWCNTs (diameter and length of 20-30 nm and 10-30 nm, respectively) were provided by National Centre for Physics, Quaid-e-Azam University, Islamabad, Pakistan. Sulfuric acid $\left(\mathrm{H}_{2} \mathrm{SO}_{4}\right) 95 \%$ and nitric acid $\left(\mathrm{HNO}_{3}\right) 70 \%$ were purchased from Merck KGaA; Darmstadt, Germany.

\subsection{Synthesis of $\mathrm{CuO}$ Nanoparticles}

$\mathrm{CuO}$ nanomaterials were successfully prepared according to a precipitation method [29]. A stoichiometric amount of copper sulfate pentahydrate $\left(\mathrm{CuSO}_{4} \cdot 5 \mathrm{H}_{2} \mathrm{O}\right.$; Merck $\mathrm{KGaA}$; Darmstadt, Germany) was dissolved in a calculated volume of distilled water to prepare a solution $(0.2 \mathrm{M})$. The $\mathrm{CuSO}_{4}$ solution was taken in a beaker and placed on a magnetic stirring hot plate, with a $\mathrm{pH}$ electrode inserted in the solution. Then, a solution of $\mathrm{NaOH}$ $(2.0 \mathrm{M})$ was added dropwise into the $\mathrm{CuSO}_{4}$ solution under continuous stirring. The addition of $\mathrm{NaOH}$ was continuously done until a $\mathrm{pH}$ of 8.5 was obtained. The solution was further stirred at $90^{\circ} \mathrm{C}$ for $1 \mathrm{~h}$, and then the resultant precipitate was recovered by filtration followed by washing with distilled water. The precipitate was calcined in a muffle furnace at $400{ }^{\circ} \mathrm{C}$ for $4 \mathrm{~h}$. Finally, a dark brown powder of $\mathrm{CuO}$ was obtained, which was cooled in a desiccator and stored in vials.

\subsection{Oxidation of MWCNTS}

MWCNTs were oxidized by an acid treatment using a procedure reported elsewhere [30]. MWCNTs were dispersed in a mixture of concentrated $\mathrm{H}_{2} \mathrm{SO}_{4}$ and $\mathrm{HNO}_{3}$ (3:1) and sonicated in an ultrasonic bath for $3 \mathrm{~h}$ at $40{ }^{\circ} \mathrm{C}$. The suspension was recovered by means of filtration and washed with distilled water until the $\mathrm{pH}$ to be neutral. The MWCNTs were then dried under vacuum in an oven at $50^{\circ} \mathrm{C}$ for $5 \mathrm{~h}$. 


\subsection{Preparation of the Polymer Composite Blend}

The PEO-CuO-MWCNT composite blend was prepared by incorporating $\mathrm{CuO}$ nanoparticles and oxidized MWCNTs as fillers in PEO polymer matrix. To prepare blend solution, $\mathrm{PEO}$ was initially dissolved in distilled water and stirred for $1 \mathrm{~h}$, and then the calculated weights of $\mathrm{CuO}$ nanoparticles and MWCNTs required for a ratio of 1:1 and 1:3 (i.e., in PEO-CuO-MWCNT:1\% and PEO-CuO-MWCNT:3\% nanocomposites) were added to the PEO solution, respectively. The mixture was homogenized by ultrasonication for approximately $4 \mathrm{~h}$ at $40^{\circ} \mathrm{C}$. Finally, the resulting homogenous dispersion with the dark brown appearance was continuously stirred to get a viscoelastic solution for the synthesis of nanofibers [31].

\subsection{Nanofibers Development via Electrospinning}

The composite nanofibers were synthesized by electrospinning. The PEO-CuOMWCNT solution was loaded in a $10 \mathrm{~mL}$ syringe fixed with a 21 gauge blunt needle linked to a high-voltage power supply. The positive electrode of the power supply was connected to the needle, while the negative one was connected to an interdigitated electrode (IDE). Aluminum foil was also attached to the negative electrode in order to collect the nanofiber for further characterization. The distance between the positive electrode (syringe) and the collector was $15 \mathrm{~cm}$, and high electrostatic voltage was applied to synthesize the nanofibers at a flow rate of $0.5 \mathrm{~mL} / \mathrm{h}$ by a syringe pump leading to the formation of a droplet of the composite solution. At a voltage of $15 \mathrm{Kv}$, the solution was sprayed on the $\mathrm{Al}$ foil and IDE screen, composite nanofibers were formed as the solvent evaporated. Graphical presentation is given in Figure S1 (Supplementary Materials).

\subsection{Characterization of PEO-CuO-MWCNT Composite Nanofibers}

XRD patterns of pure PEO, CuO nanoparticles, MWCNTs and PEO-CuO-MWCNT nanofibers were performed using an X-ray diffractometer (Model JDX-9C, JEOL; Akishima, Tokyo, Japan) at room temperature. The morphology of the samples was examined by scanning electron microscope (Model JEOL-JSM-5910; Akishima, Tokyo, Japan), while the elemental analysis of the composite and the precursor materials was investigated by EDS analysis (Oxford Instruments, High Wycombe, United Kingdom). Fourier transform infrared (FTIR) spectra of pure PEO, CuO nanoparticles, MWCNTs and nanocomposites were taken through an FTIR spectrophotometer (Shimadzu FTIR-820.1 PC; Tokyo, Japan).

\subsection{Humidity Sensing Experiments}

The humidity sensing properties of the composite nanofibers were studied by measuring their capacitance and resistance at different RH levels using a digital LCR meter (Keysight E4980; Keysight Technologies, Santa Clara, CA, USA). The reference humidity sensor (DHT11) was combined with a microcontroller (ARDUINO UNO 328; Somerville, MA, USA), and both were connected to a computer through an RS232 card. The composite nanofibers were loaded on the interdigitated electrode (IDE) and connected to the LCR meter. The IDE electrode was placed in a moisture chamber along with the reference sensor, while atmospheres containing various humidity levels were adjusted passing dry nitrogen and air saturated with vapors of deionized water. The moisture chamber was sealed, and the change in resistance and capacitance was recorded at every $60 \mathrm{~s}$ under varying $\mathrm{RH}$ between 30 and $90 \%$. The values of the resistance and capacitance changes with $\% \mathrm{RH}$ were recorded and digitized, respectively.

\section{Results and Discussion}

\subsection{Characterization of Composite Nanofibers}

3.1.1. SEM Analysis

The morphological features of the composite nanofibers were examined by Scanning Electron Microscopy (SEM). Figure 1a-d shows the SEM micrographs of pure PEO, CuO nanoparticles, MWCNTs and PEO-CuO-MWCNT nanocomposites. The SEM image of 
pure PEO is displayed in Figure 1a, revealing a compact flaky morphology; the granules seem to be agglomerated and highly dense, thus confirming its crystalline nature as also indicated by XRD analysis [32]. Figure $1 \mathrm{~b}$ displays the micrograph of $\mathrm{CuO}$ nanoparticles, which shows a homogeneous distribution of fine spherical particles of $\mathrm{CuO}$ nanoparticles [33]. The micrograph of MWCNTs (Figure 1c) shows that this highly intertwisted configuration could be assigned to the functionalization of MWCNTs [34]. The SEM micrographs of PEO-CuO-MWCNT: 1\% and PEO-CuO-MWCNT: 3\% (Figure 1d,e) exhibit very fine fibers with uniform and smooth surfaces, indicating the uniform dispersion fillers in the polymer matrix. However, in the case of PEO-CuO-MWCNT (3\%), some agglomerates may be observed, which may be caused due to high amounts of $\mathrm{CuO}$ and MWCNT.
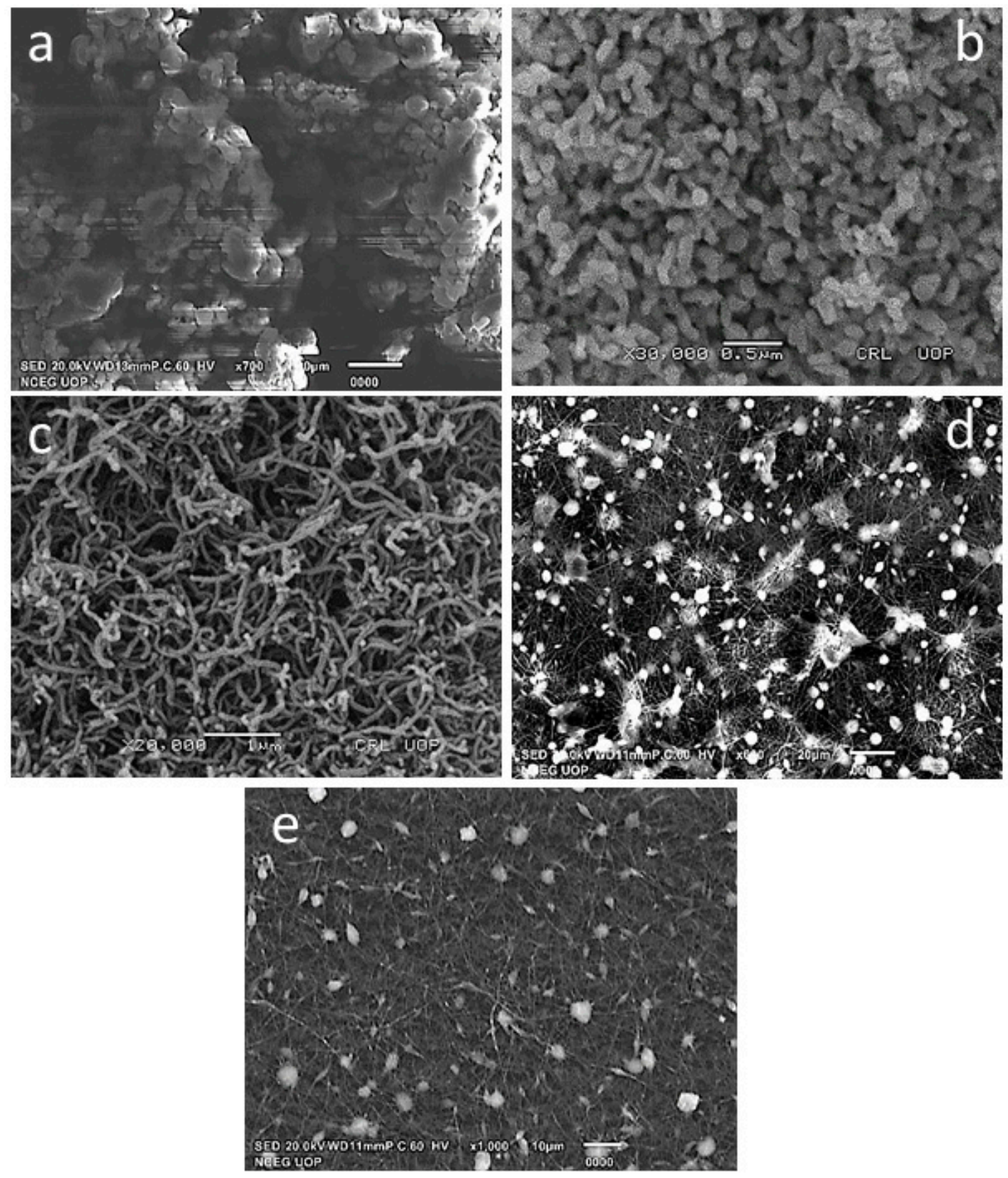

Figure 1. SEM micrographs of (a) pure PEO (b) CuO nanoparticles (c) multi-walled carbon nanotubes (MWCNT) (d) PEO: CuO: MWCNT: $1 \%$ nanofibers (e) PEO: CuO: MWCNT: 3\% nanofibers. 


\subsubsection{X-ray Diffraction Analysis}

The X-ray diffraction (XRD) patterns of pure PEO, CuO nanoparticles, MWCNTs and composite nanofibers are illustrated in Figure S2 (Supplementary Materials). The XRD pattern of pure PEO (Figure S2a) shows two sharp peaks at $19.22^{\circ}$ and $23.1^{\circ}$, attributed to its highly crystalline structure [35]. The XRD pattern of $\mathrm{CuO}$ nanoparticles (Figure $\mathrm{S} 2 \mathrm{~b}$ ) confirmed the two characteristics peaks at $35.57^{\circ}$ and $38.85^{\circ}$, showing a high crystallinity phase of $\mathrm{CuO}$ [36]. Finally, the XRD pattern of MWCNTs (Figure S2c) shows a sharp and strong diffraction peak at $25.70^{\circ}$ [37], attributed to the crystalline phase of CNTs.

In the XRD patterns of PEO-CuO-MWCNT: 1\% and PEO-CuO-MWCNT: 3\% (Figure S2d,e), the characteristic peaks corresponding to PEO and MWCNT can be observed. In the case of PEO-CuO-MWCNT: 1\%, the crystalline peaks for MWCNT and $\mathrm{CuO}$ are less evident due to the lower concentration ratio of the fillers in the PEO matrix. However, the XRD pattern of PEO-CuO-MWCNT: 3\% retains the crystalline peaks of $\mathrm{CuO}$ and MWCNT. Hence, the crystallinity of the composites seems to be maintained after the addition of MWCNTs and $\mathrm{CuO}$ nanoparticles [38].

\subsubsection{FTIR Spectroscopy}

The FTIR spectra of the polymer matrix, i.e., PEO, fillers (CuO and MWCNTs) and the composite nanofibers, are shown in Figure 2. The FTIR spectrum of pure PEO shows a strong peak at $2874.90 \mathrm{~cm}^{-1}$, which is related to asymmetric $\mathrm{C}-\mathrm{H}$ stretching vibrations of $\mathrm{CH}_{2}$ groups. The significant central peak at $1468.33 \mathrm{~cm}^{-1}$ is due to asymmetric bending vibrations of $\mathrm{CH}_{2}$ groups, while a strong intense peak at $1102.06 \mathrm{~cm}^{-1}$ is attributed to the asymmetric $\mathrm{C}-\mathrm{O}-\mathrm{C}$ stretching for epoxide groups. These configurations are in agreement with the structural features of PEO polymer [39]. The FTIR spectrum of $\mathrm{CuO}$ nanoparticles is shown in (Figure 2), presenting a major peak at $607.90 \mathrm{~cm}^{-1}$ [40]. The spectrum of MWCNTs shows two strong bands at 3435 and $1717 \mathrm{~cm}^{-1}$, representing the $\mathrm{O}-\mathrm{H}$ and $\mathrm{C}=\mathrm{O}$ of carboxylic acids, respectively [37], this indicates the successful oxidation of MWCNTs.

The spectra of PEO-CuO-MWCNT: 1\% and PEO-CuO-MWCNT: 3\% nanocomposites are displayed in Figure 2. It is obvious that FTIR spectra for both composites show peaks corresponding to $\mathrm{CuO}, \mathrm{MWCNT}$ and $\mathrm{PEO}$, confirming the presence of these components in the composite samples. However, it should be noted that, in the case of PEO-CuO-MWCNT: $3 \%$ nanocomposite, the intensity of the peaks positioned at 2874.90 and $1102.06 \mathrm{~cm}^{-1}$ is slightly decreased, which may be attributed to the interaction between the ether group of the poly ethylene oxide and the hydroxyl one of the oxidized MWCNT, which are linked through hydrogen bonding [41]. Since the amount of MWCNT is higher in the composite containing filler $3 \%$, the extent of interaction is larger, causing an obvious decrease in peak intensity compared to the nanocomposite with $1 \%$ MWCNT. All the configurations in the nanocomposite samples give peaks at respective wavelengths, as mentioned above [41].

\subsubsection{EDS Analysis}

Figure S3a-d displays the energy dispersive spectroscopy (EDS) profiles and the atomic ratio of MWCNTs, pure polyethylene oxide (PEO) and composite nanofibers PEO$\mathrm{CuO}-\mathrm{MWCNT}$. The elemental composition of MWCNTs confirms the presence of about $84 \%$ of $\mathrm{C}$ and $16 \%$ of $\mathrm{O}$. The significant amount of oxygen and carbon suggests the successful oxidation by nitric acid and sulfuric acid, along with some impurities of $\mathrm{Al}$ and $\mathrm{Si}$ as residues of the various reagents involved during the chemical treatment. EDS analysis of pure PEO matrix shows about $58.50 \%$ carbon and $36 \%$ carbon, confirming the composition of PEO [42]. The elemental composition of composite nanofibers, i.e., PEO-CuO-MWCNT: $1 \%$ and PEO-CuO-MWCNT: $3 \%$ shows the presence of $\mathrm{C}, \mathrm{O}$ and $\mathrm{Cu}$, which is in agreement with their chemical composition [43]. In the case of PEO-CuO-MWCNT: $1 \%$ nanofiber, the amount of $\mathrm{Cu}$ is shown to be $0.5 \%$, whereas in that of PEO-CuO-MWCNT: $3 \%$, it is $\sim 1.89 \%$. Although the values seem to be slightly lower than the theoretical values of 1 and $3 \%$, this behavior might be attributed to the low sensitivity of the EDS analysis in a very low concentration of elements. 


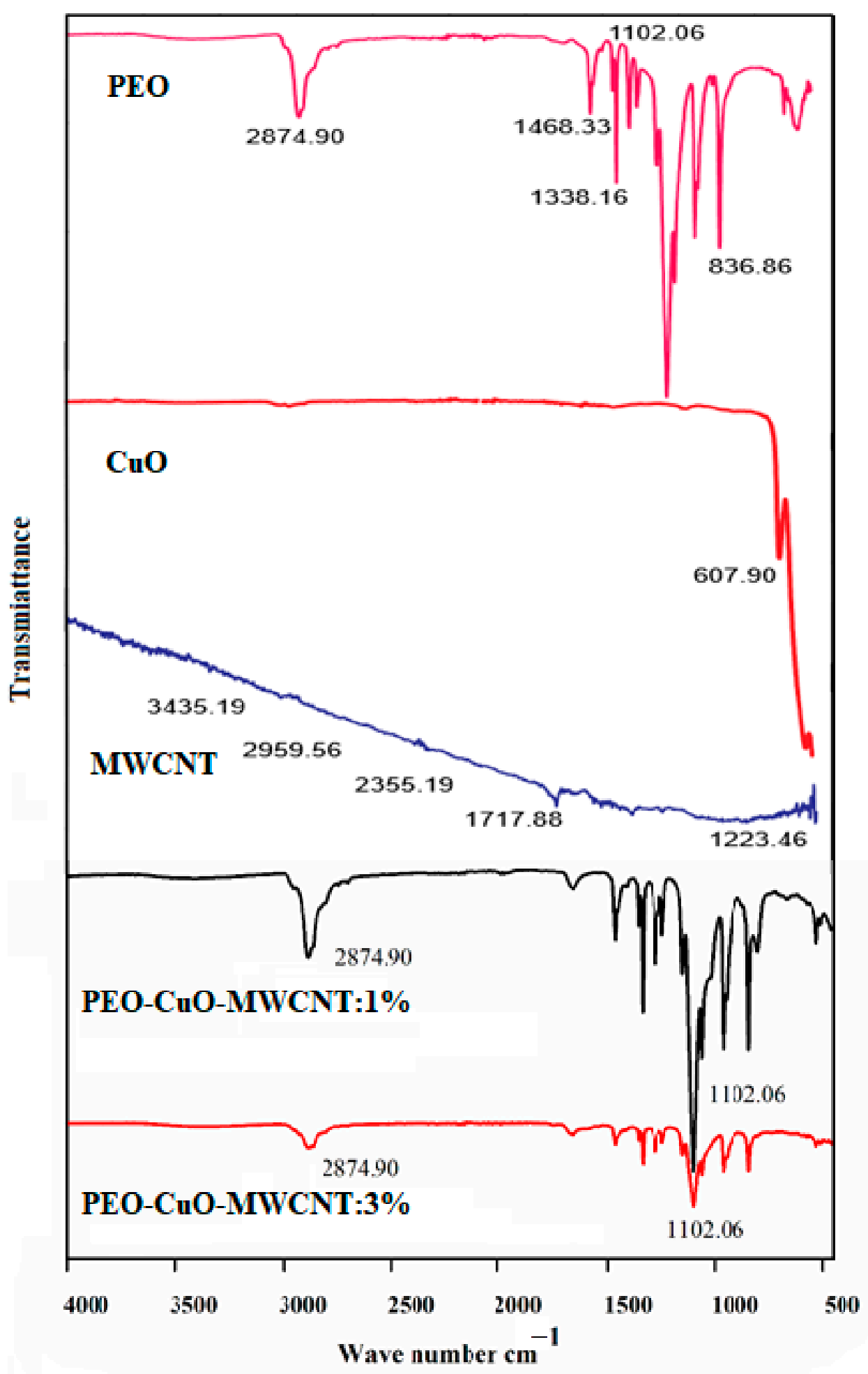

Figure 2. FTIR spectra of pure PEO (purple), CuO nanoparticles (red) and MWCNTs (blue), PEOCuO-MWCNT: 1\% (black) and PEO-CuO-MWCNT: 3\% (orange) composite nanofibers.

\subsection{Humidity Sensing Efficiency of PEO-CuO-MWCNT Composite Nanofibers}

The humidity sensing performance of PEO-CuO-MWCNT composite nanofibers was investigated by measuring its capacitance and resistivity response in various levels of $\mathrm{RH}$ as a function of frequency. Initial experiments showed that PEO- composite nanofibers with $1 \% \mathrm{CuO}$ presented a significant resistivity response, better than the respective capacitance response upon changing the $\mathrm{RH}$. 


\subsubsection{Sensitivity and Response}

It has been shown that frequency has a major role and impact on the humidity sensing performance. The results of humidity sensing efficiency of the composite nanofibers are investigated at various input frequencies such as $1 \mathrm{KHz}, 10 \mathrm{kHz}, 100 \mathrm{KHz}$ and $1 \mathrm{MHz}$. Figures 3-8 indicate the resistivity and capacitance response, of PEO-CuO-MWCNT: 1\% and PEO-CuO-MWCNT: 3\% composite nanofibers upon \% RH, ranging from 30-90\%. When RH increases, the capacitance and resistance of nanocomposites also increase along with the frequency. Conversely, it is observed that at low frequencies, the sensor shows high capacitive and resistive response, as compared to high frequency [44]. The following equation is used to determine the sensitivity of the sensor:

$$
\begin{aligned}
& \text { Resistive Sensitivity }(S)=\frac{\Delta R / R_{0}}{\Delta(\% R H)} \\
& \text { Capacitive Sensitivity }(S)=\frac{\Delta C / C_{0}}{\Delta(\% R H)}
\end{aligned}
$$

where $\Delta \mathrm{R}$ and $\Delta \mathrm{C}$ are the changes in resistance and capacitance when exposed to fluctuating humidity values with respect to initial value $\mathrm{R}_{0}$ or $\mathrm{C}_{0}$.

Our results showed that the resistance and capacitance of the sensor significantly increased when $\mathrm{RH}$ value changed from $30-90 \% \mathrm{RH}$. This significant increase in capacitance could be associated with the adsorption of water molecules on the surface of the sensor, which directly depends on the RH level [4]. In the adsorption process, due to an electrical potential gap, part of the electrons will be moved from the adsorbed $\mathrm{H}_{2} \mathrm{O}$ molecules to MWCNTs. The higher the amount of $\mathrm{RH}$, the greater the adsorption of $\mathrm{H}_{2} \mathrm{O}$ molecules and the more electrons are transferred. The PEO-MWCNT-CuO behaves as a semiconductor, containing electrons (-vie charges) and holes (+ive charges). In the present case, the electrons are minority carriers and the holes are the majority carrier. As electron (minority carrier) from water molecules are transferred, this will lower the concentration of majority carrier, i.e., +ive charges (holes), thereby resulting in an increase in the resistance of the sensor [45].

The remarkable increase of resistivity response was measured over a $\% \mathrm{RH}$ range from 30 to $90 \%$ at four different frequencies, i.e., $1 \mathrm{KHz}, 10 \mathrm{KHz}, 100 \mathrm{KHz}$ and $1 \mathrm{MHz}$, respectively. It was observed that the resistance at lower frequencies $(1 \mathrm{KHz}$ and $10 \mathrm{KHz})$ enhances proportionally to $\mathrm{RH}$. This resistance change of the sensor is displayed in Figure 3 . The data show that at $30 \% \mathrm{RH}$, the resistivity shown by $1 \% \mathrm{wt}$ nanocomposite is about $1.5 \times 10^{5} \Omega$, which is smaller than $6.7 \times 10^{6} \Omega$ at $90 \% \mathrm{RH}$ at $1 \mathrm{KHz}$ frequency [46]. At low frequencies, the PEO-MWCNT-CuO: 1\%-based sensor exhibited the highest resistivity sensitivity of $\sim 3798.2 \%$, as displayed in Figure 4 , with a slightly low correlation in resistance $\left(\mathrm{R}^{2}\right)$ as compared to PEO-MWCNT-CuO: $3 \%$ nanocomposite-based sensor, as shown in Figure 5 .

The capacitance response of PEO-CuO-MWCNT: 3\% nanocomposites drastically increased from $1.09 \times 10^{-10} \mathrm{~F}$ (for $30 \% \mathrm{RH}$ ) to $7.9 \times 10^{-8} \mathrm{~F}$ (for $90 \% \mathrm{RH}$ ) as shown in Figure 6, while a frequency shift can be observed from $1 \mathrm{KHz}$ to $1 \mathrm{MHz}$ [47]. The high capacitance response of PEO-CuO-MWCNT: 3\% composite nanofibers can be ascribed to the formation of multilayers of water on the exterior of the sensor that increases the dielectric constant, leading to an abrupt capacitance change [48]. However, the ideal situation for a sensing material is revealed when the humidity is low, and thus less water is absorbed. Subsequently, leak conduction occurs by absorbing water molecules. The capacitance $C$ of the sensing material with leak conduction can be illustrated by the following equation:

$$
\mathrm{C}=\mathcal{E} * \mathrm{C}_{0}=\mathcal{E} \mathrm{r}-i \gamma / \omega \mathcal{E}_{0} \mathrm{C}_{0}
$$

where $\mathcal{E}$ is the complex dielectric constant, $\mathrm{C}_{0}$ and $\mathcal{E}$ r are capacitance and relative dielectric parameter of an ideal capacitor, $\omega$ stands for frequency, $\gamma$ is the conductivity and $\mathcal{E}_{0}$ presents the permittivity in free space. 
From Equation (3), it can be concluded that the capacitance of the sensing material is directly proportional to $\gamma$ and inversely proportional to frequency [49]. Moreover, Figure 7 shows the sensor exhibited high capacitive sensitivity of $\sim 53,837.6 \%$ at lower frequencies such as $1 \mathrm{KHz}$ at $90 \% \mathrm{RH}$ [50] than $\sim 3784.81 \%$ resistivity sensitivity. Though the sensor shows a high sensitivity within the RH range of $30-70 \%$, the response or sensitivity in the $\mathrm{RH}$ range of $70-90 \% \mathrm{RH}$ is also considerable. PEO-CuO-MWCN: $3 \%$ nanocomposite showed improved linear regression coefficient $\left(\mathrm{R}^{2}\right)$ with a positive slop over wide humidity range levels such as 30-90\% RH as displayed in Figure 8.

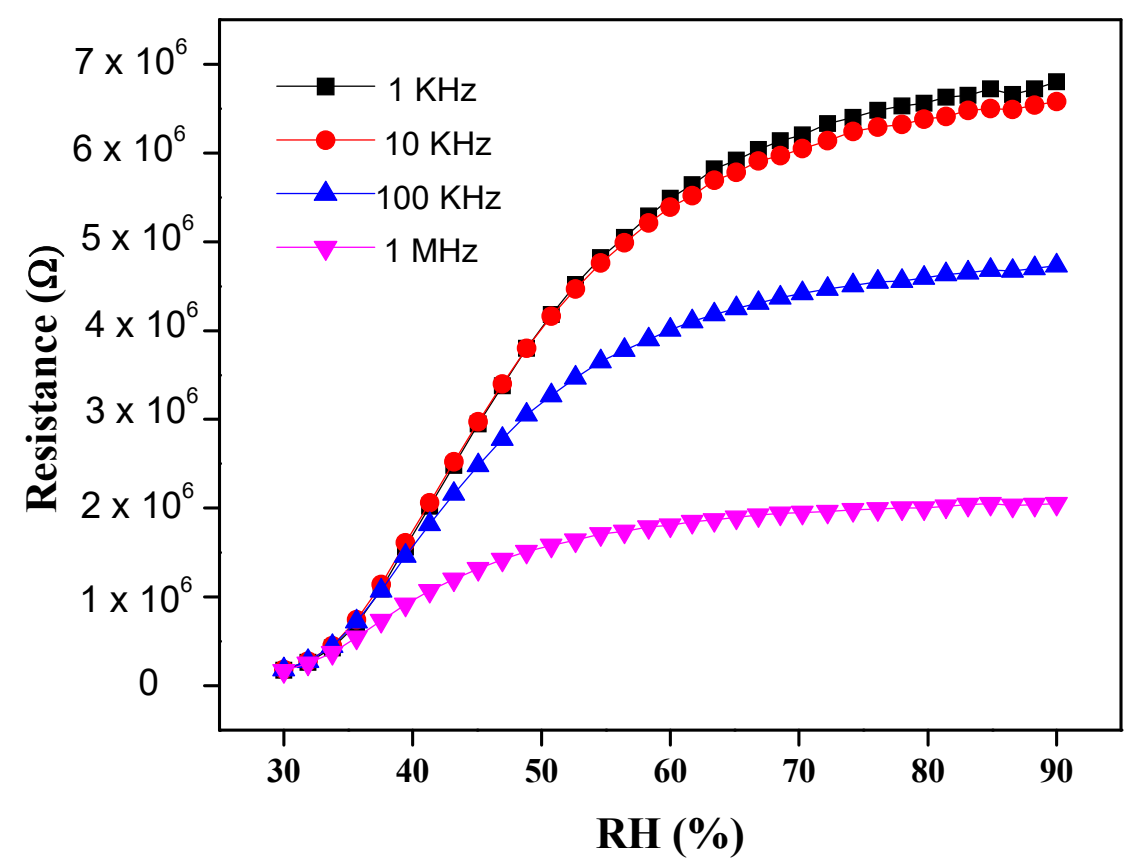

Figure 3. Resistivity response of PEO-CuO-MWCNT: $1 \%$ nanocomposite at different $\%$ RH.

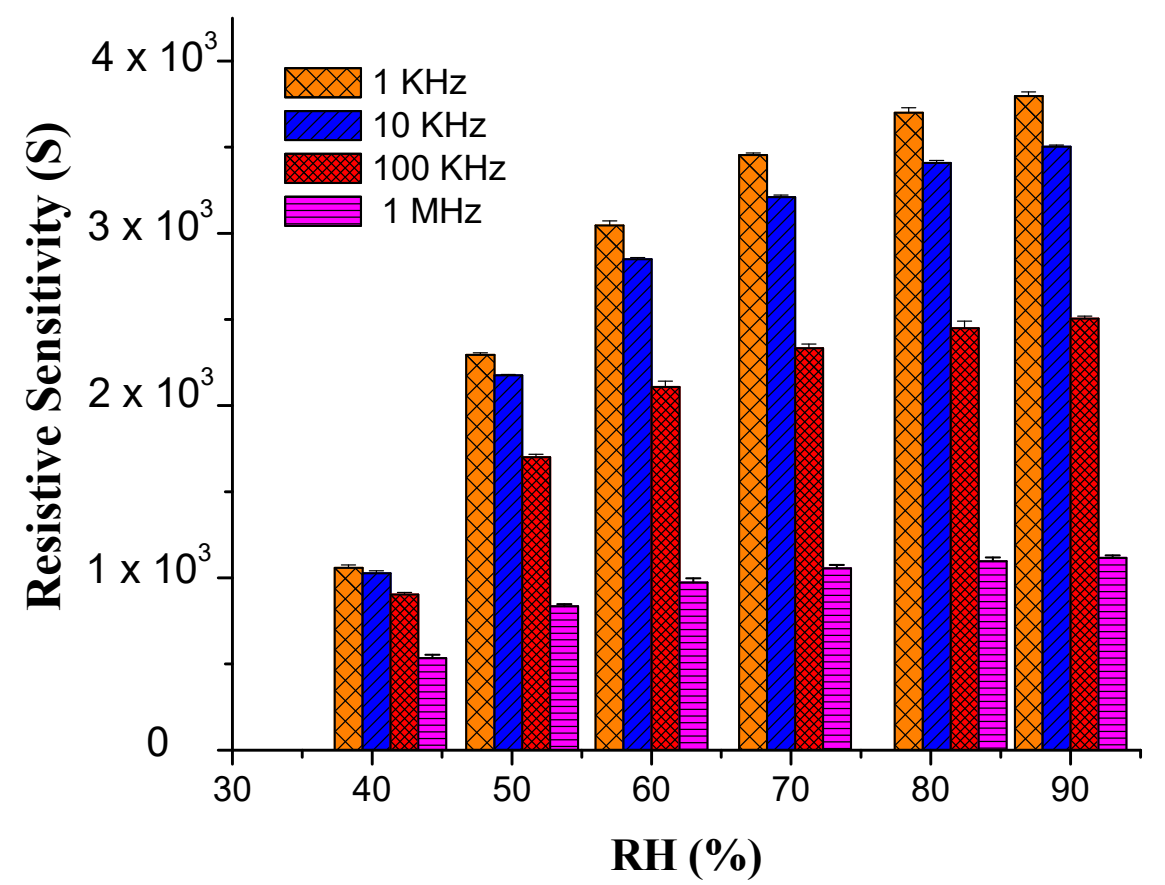

Figure 4. Resistivity Sensitivity of PEO-CuO-MWCNT:1\% nanocomposite at different \% RH. 


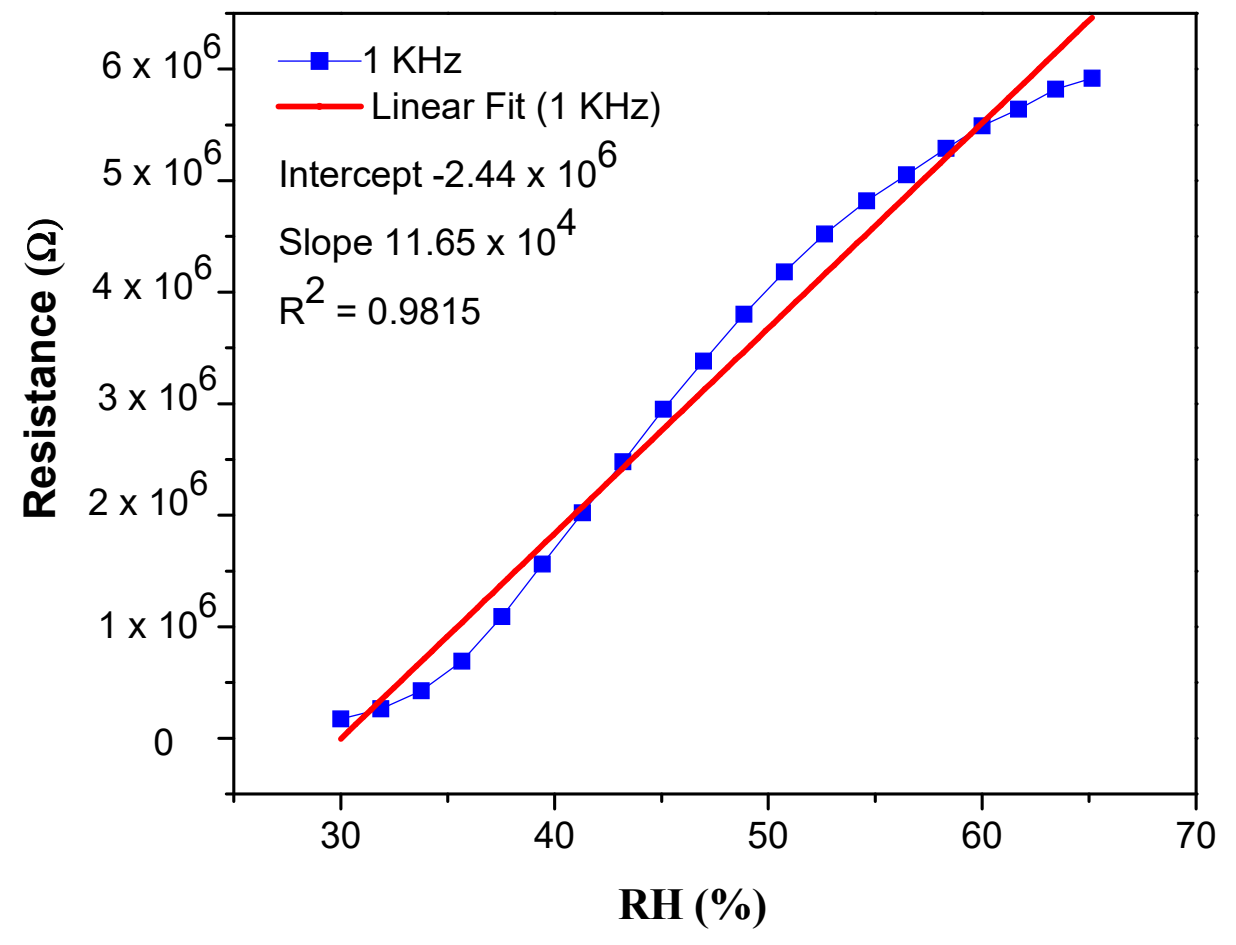

Figure 5. Resistive linearity of PEO-CuO-MWCNT: 1\% nanocomposites.

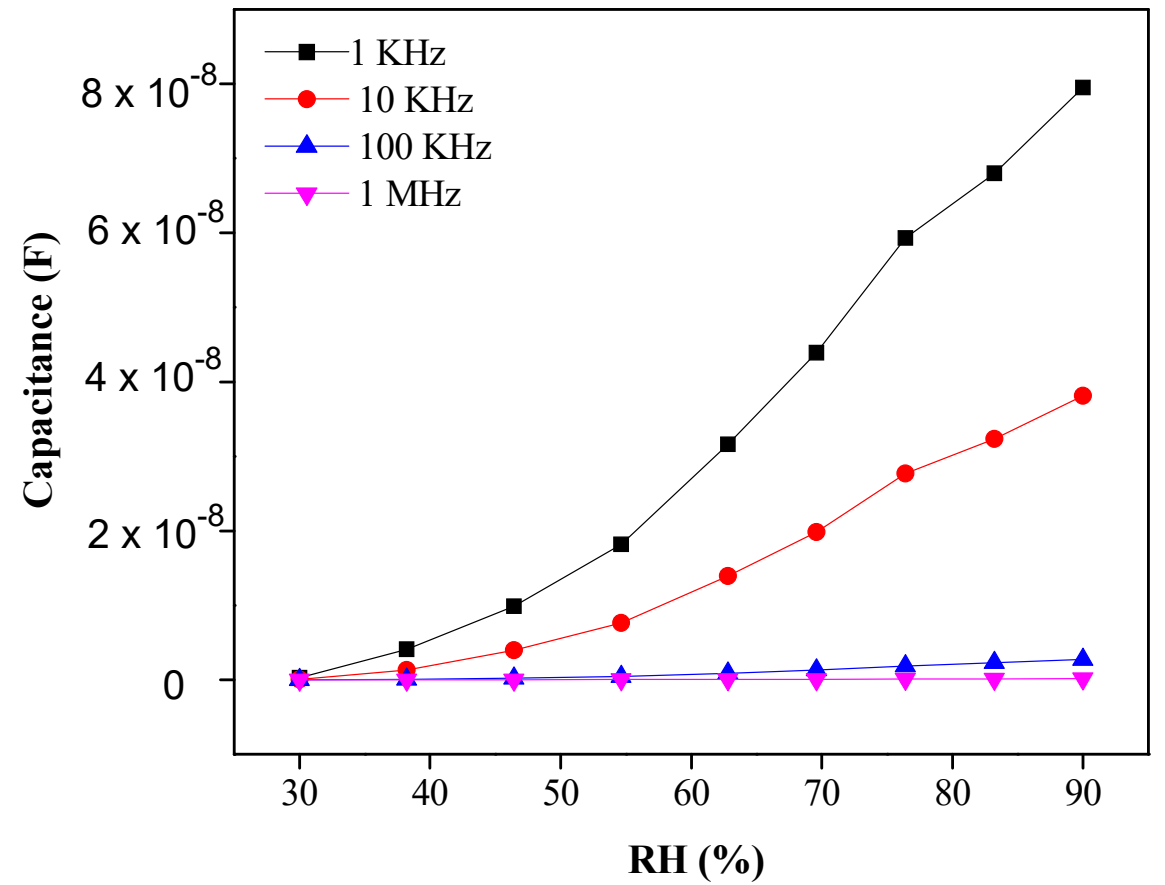

Figure 6. Capacitance response of PEO-CuO-MWCNT: $3 \%$ nanocomposite at different \% RH. 


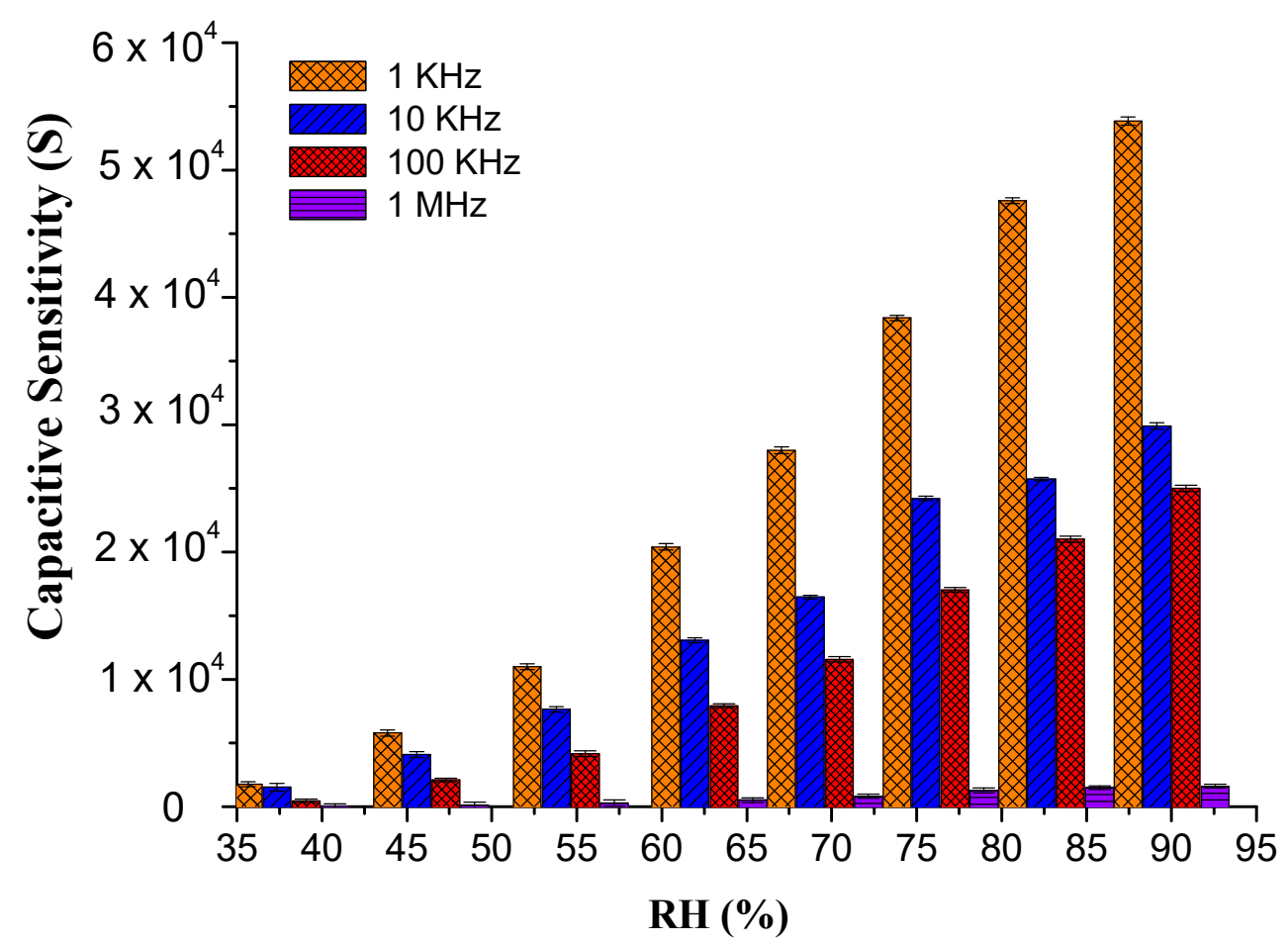

Figure 7. Capacitive Sensitivity of PEO-CuO-MWCNT: $3 \%$ nanocomposite at different $\%$ RH.

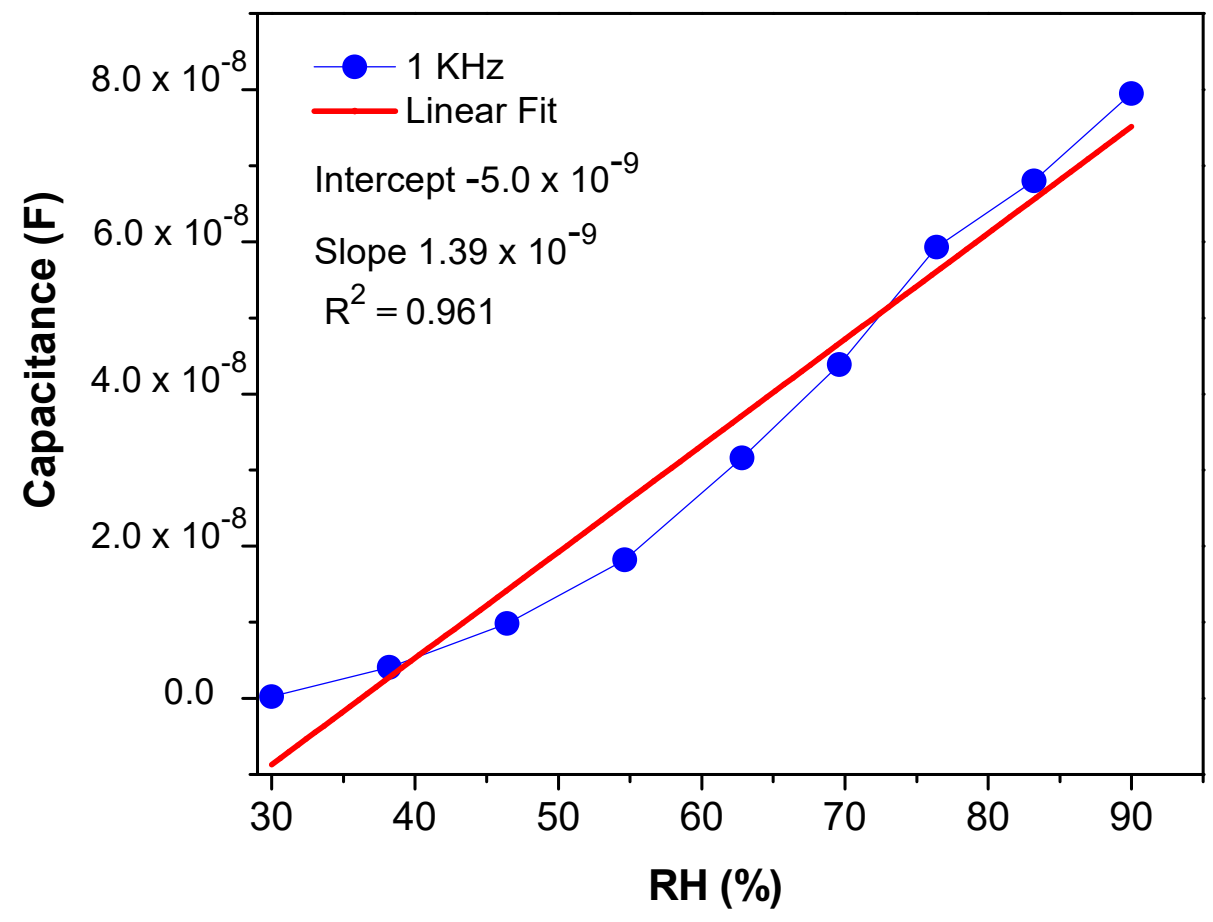

Figure 8. Capacitive linearity of PEO-MWCNT-CuO: $3 \%$ nanocomposites.

\subsubsection{Response and Recovery Time}

One of the considerable parameters for the fabrication of excellent and economical humidity sensors is their fast response and recovery time. Usually, response and recovery times are measured in 10-90\% RH, but in the present case, the response of the sensor below 30\% RH was negligible; hence, measurement was carried out between 30 and $90 \% \mathrm{RH}$. When air humidity is suddenly varied from 30 to $90 \% \mathrm{RH}$, the response and recovery time can be verified by the capacitive and resistive variation of the humidity 
sensor. The response or recovery time is the time responsible for causing a $90 \%$ change of their original value when increasing the humidity from a low to a high degree or vice versa, respectively. Due to the hydrophilic nature of the PEO matric, and its large surface area, it is perceived that composite nanofibers allow faster adsorption of water molecules. In this context, the response and recovery time of resistivity and capacitance response of PEO-CuO-MWCNT: $1 \%$ and PEO-CuO-MWCNT: $3 \%$ composite nanofibers have been presented in Figures 9 and 10, at four different frequencies, from $30 \%$ to $90 \% \mathrm{RH}$. The response time for resistivity response is measured to be $3 \mathrm{~s}$ and $22 \mathrm{~s}$ respectively when humidity changes from 30 to $90 \%$. The response and recovery time for a capacitance humidity sensor is measured to be $20 \mathrm{~s}$ and $11 \mathrm{~s}$ respectively, for 30 to $90 \% \mathrm{RH}$.

Owing to their low density and high aspect ratio, carbon nanotubes have proven to be ideal fillers for designing diverse polymer composites with enhanced mechanical performance, high electrical conductance and multi-functional properties [51]. Additionally, the oxyfunctionalities incorporated during the oxidation of MWCNTs may provide more active sites for the interaction of water molecules. Likewise, $\mathrm{CuO}$ is assumed to enhance the interfacial characteristics and porosity of the polymeric matrix, enabling it to efficiently absorb the water molecules [52]. Since PEO is a hydrophilic polymer, the incorporation of $\mathrm{CuO}$ nanoparticles and MWCNTs into it results in nanocomposites that exhibit a fast response. $\mathrm{CuO}$ nanoparticles and MWCNTs provide large surface-active sites for the adsorption of moisture [53]. This adsorption occurs due to the functional groups of MWCNTs and PEO, through hydrogen bonds formation or through weak physical forces with the adsorption site in the large surface area of nanocomposites [54]. However, the hydrophilic nature of the composites delays the water release; therefore, recovery time was longer at $22 \mathrm{~s}$ and $11 \mathrm{~s}$. At high frequencies $(1 \mathrm{MHz}$ or $100 \mathrm{KHz})$, the response and recovery time is much lower for the capacitance humidity sensor, than the resistivity humidity sensor, as depicted in Figures 9 and 10.

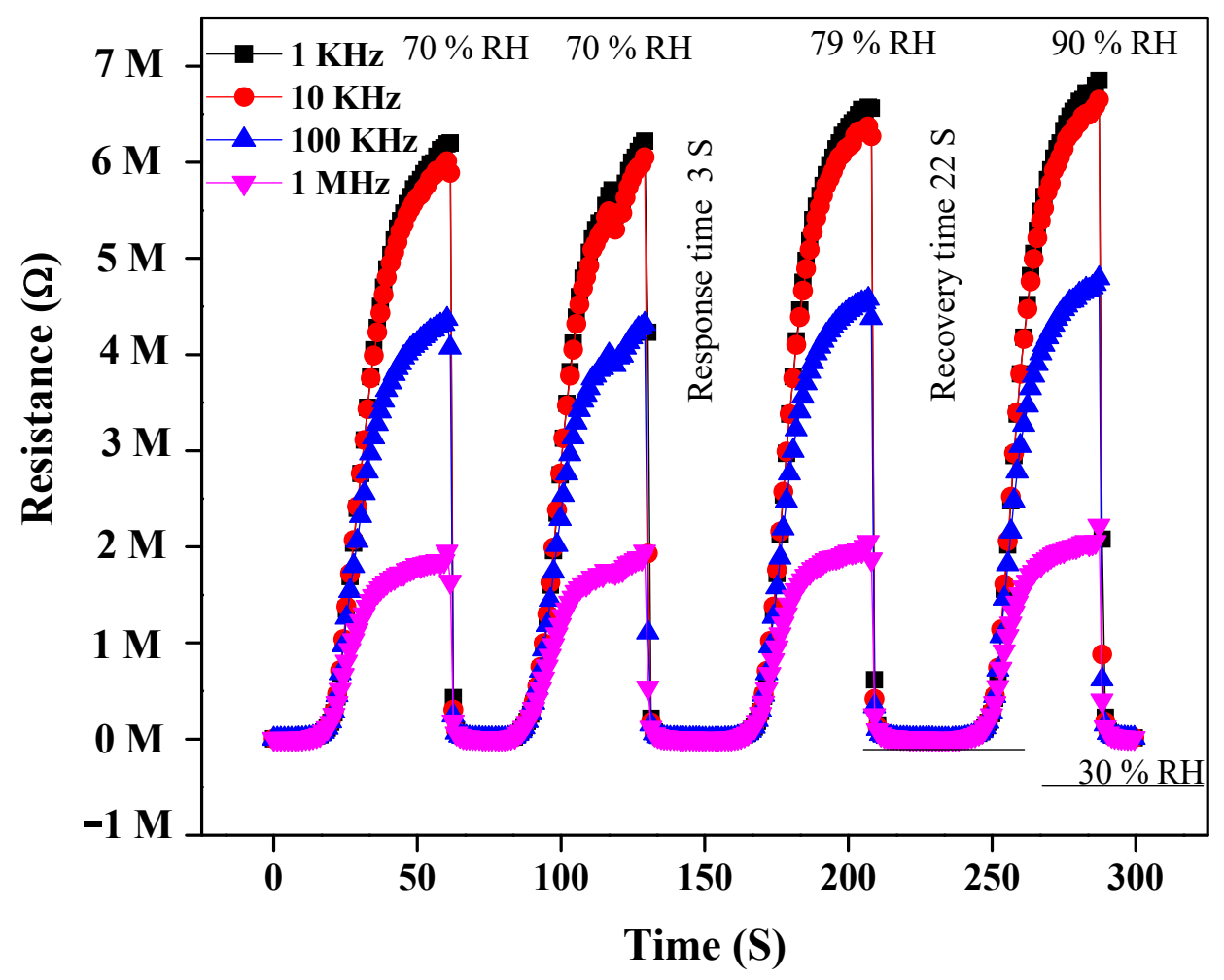

Figure 9. Resistivity response/recovery time for PEO-CuO-MWCNT: 1\% nanocomposites. 


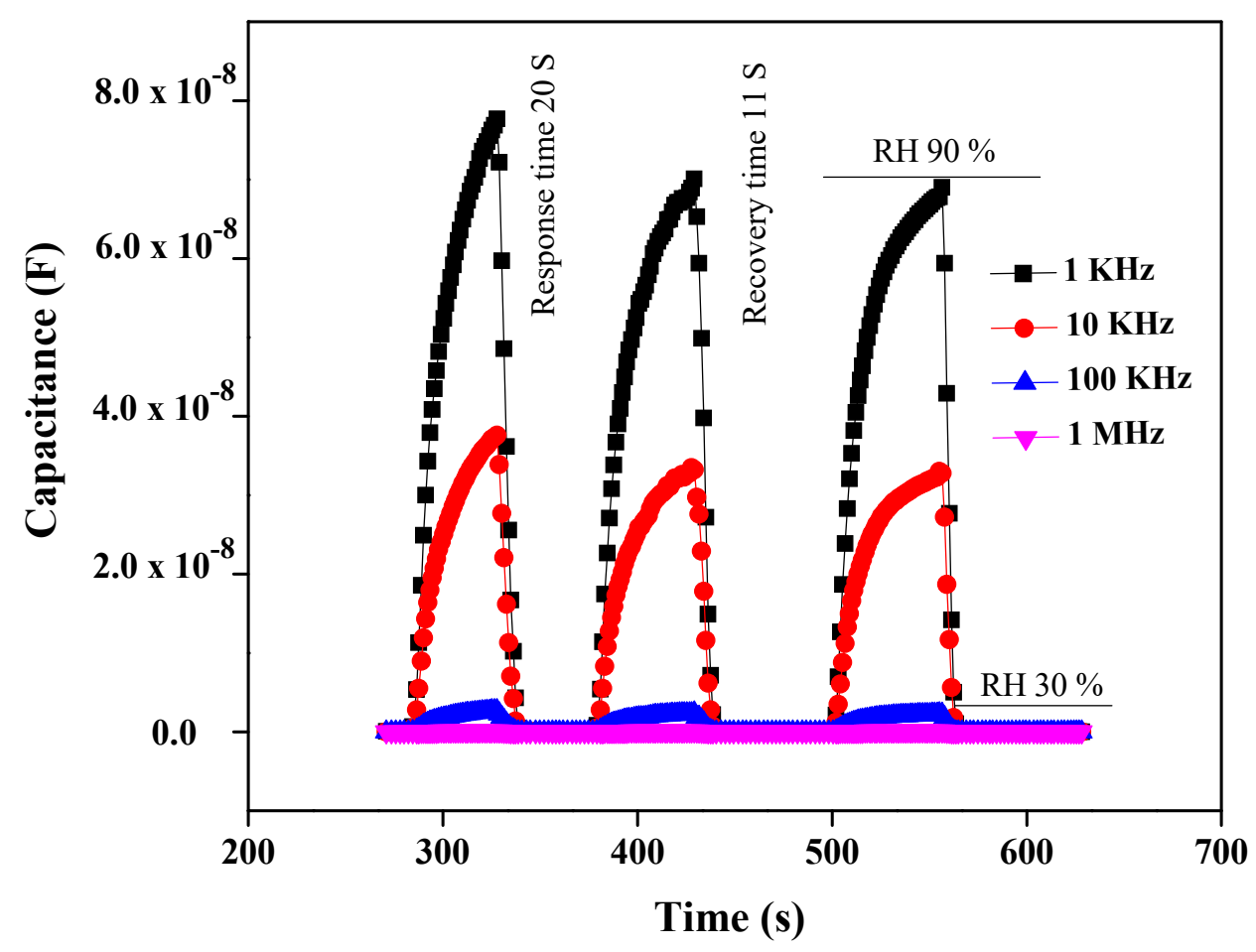

Figure 10. Capacitance response/recovery time for PEO-MWCNT-CuO: 3\% nanocomposites.

\subsubsection{Humidity Sensing Mechanism}

The humidity sensing mechanism for the adsorption of water molecules on the surface of PEO-CuO-MWCNTs is displayed in Figure 11. The rough and smooth surface of nanocomposites can be indirectly detected by the addition of $\mathrm{CuO}$ nanoparticles inside the hydrophilic polymer matrix to improve the large surface area of the nanocomposite, which enables more water molecules to be adsorbed on the sensing material [5]. On the contrary, the formation of hydrogen bonds between hydrophilic PEO and water molecules enhances the humidity sensing response [10]. Moreover, the large surface area of MWCNT nanostructures as well as the incorporation of $-\mathrm{COOH}$ functional side groups create active sites for the adsorption of vapor molecules [55].

To explain the humidity sensing mechanism, two types of adsorption interactions were considered i.e., chemisorption and physisorption [4]. The current study initiated at low RH the nanofiber composite exposed to water molecules. The additional water molecules were adsorbed on the surface of the hydrophilic PEO through intermolecular hydrogen bonding, identified as chemisorbed layer [48]. With increasing RH level, a water multilayer was formed between two adjacent hydroxyl groups via hydrogen bonding, leading to the formation of a physisorption layer [56]. Water molecule clustering was also noted [57]. However, since the increase in capacitance is very small as the RH increased from 30 to $50 \%$, it was concluded that water molecules adsorbed in the first layer had a very small contribution to the dielectric constant. This can be attributed to the fact that chemisorbed water molecules cannot be freely oriented with an external applied electric field, due to their bonding (hydrogen bonding) with composite nanofibers [58], which leads to very small change in dielectric constant and thereby causes little variation in capacitance. Therefore, it was observed that there is significant increase in capacitance around $50 \% \mathrm{RH}$. This indicates that at 50\% RH, the first layer was almost completed and the second layer's formation has begun. Hence, the capacitance and resistance are drastically increased between 50 and $90 \% \mathrm{RH}$ due to the formation of a multilayer in the sensing material. Since the PEO-MWCNT-CuO: $1 \%$ composite nanofibers exhibited resistive response whereas $\mathrm{PEO}-\mathrm{MWCNT}-\mathrm{CuO}: 3 \%$ showed a capacitive response, this indicates that with the increasing of the filler's concentration, the behavior of the composite changed from resistive to capacitive. This may be attributed to the conductive nature of both fillers, 
i.e., $\mathrm{MWCNT}$ and $\mathrm{CuO}$, in the case of $\mathrm{PEO}-\mathrm{MWCNT}-\mathrm{CuO}: 1 \%$ nanocomposites where the concentration of $\mathrm{CuO}$ was smaller, and hence the conductance is less, and the dielectric constant was negligible. Consequently, due to very low dielectric constant, the resistivity of the composite is higher than its capacitance, which is why it shows high resistive response. On the other hand, in the case of the PEO-MWCNT-CuO: $3 \%$ nanofibers-based sensor, the high concentration of conducting fillers leads to increased dielectric constant, due to which the sensor exhibits capacitive response with varying $\mathrm{RH}$.

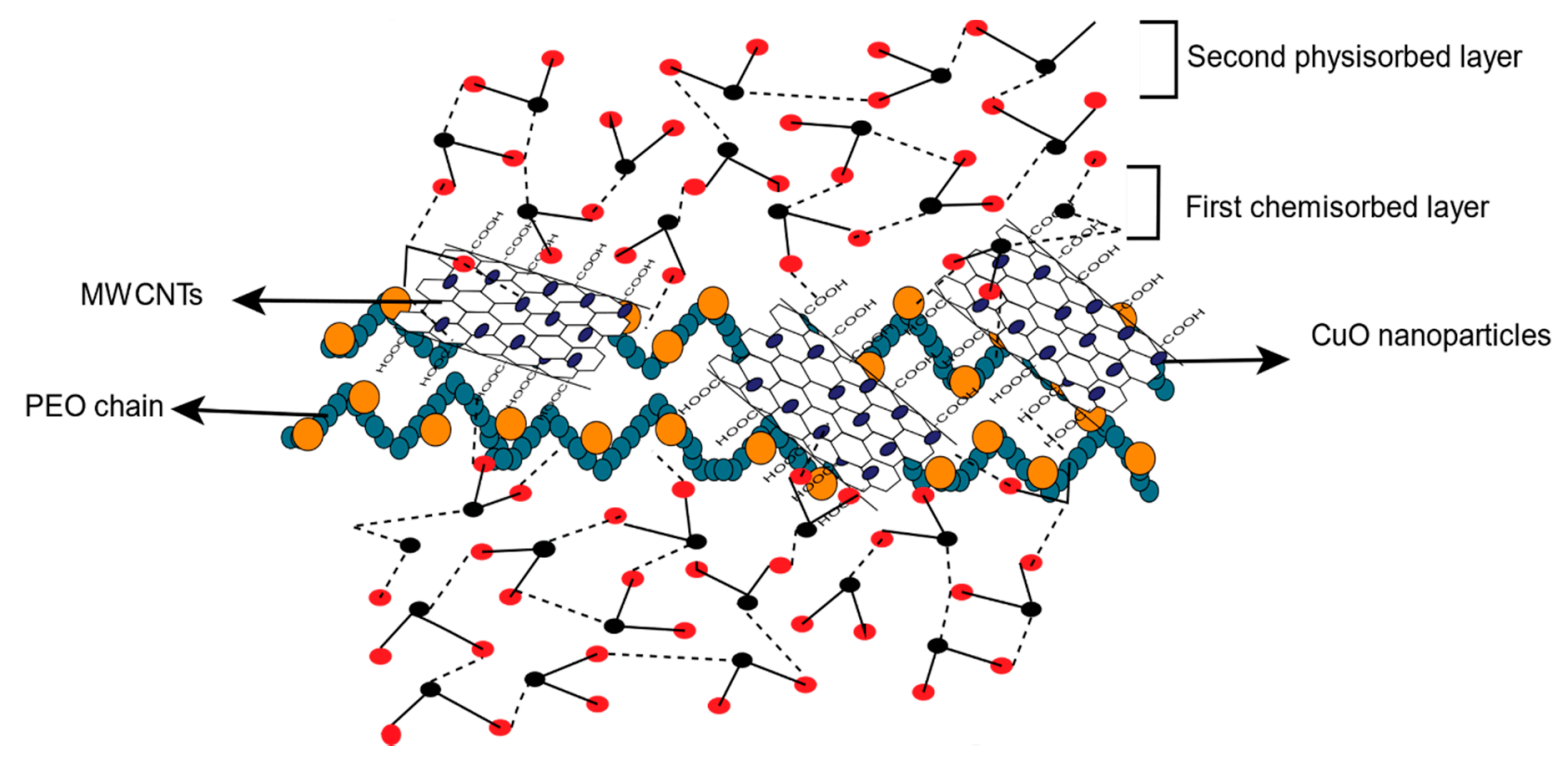

Figure 11. Schematic presentation of adsorption of $\mathrm{H}_{2} \mathrm{O}$ molecules on the surface of PEO-MWCNT-CuO nanocomposites.

\subsection{Comparative Efficiencies of the Sensors}

Table 1 displays the comparison between the resistive and capacitive response to $\% \mathrm{RH}$ different sensor materials reported in the literature, along with their recovery and response time. It is evident that the sensor developed in the current study i.e., $\mathrm{PEO}-\mathrm{MWCNT}-\mathrm{CuO}$ : $1 \%$ and PEO-MWCNT-CuO: 3\%, exhibited much higher sensitivity of $3798.2 \%$ and $53837.6 \%$ with response and recovery times of $3 \mathrm{~s}$ and $22 \mathrm{~s}$ and at $20 \mathrm{~s}$ and $11 \mathrm{~s}$, respectively, for $30 \%$ to $90 \% \mathrm{RH}$. Thus, the comparative analysis concludes that the sensors used in this study showed higher sensitivity in relation to other previously reported humidity sensors. Finally, the response and recovery time of current sensors are rapid compared to the reported ones in the literature. Thus, these humidity sensors can be potentially used for practical applications.

Table 1. A comparison of the resistive and capacitive response to $\mathrm{RH}$.

\begin{tabular}{|c|c|c|c|c|c|c|}
\hline Sensing Material & Type & RH (\%) & Sensitivity & $\mathbf{R}^{2}$ & Response/Recovery Time & Ref. \\
\hline GO/MWCNT & Capacitive & $11-97$ & $7980 \%$ & - & $5 \mathrm{~s} / 2.5 \mathrm{~s}$ & [59] \\
\hline MWCNT/Nafion nanofibers film & SAWR & $10-80$ & $427.6 \%$ & 0.987 & $3 \mathrm{~s}$ at $63 \%$ & [60] \\
\hline PANI/PVB nanofibers & SAWR & $20-90$ & $\sim 75 \mathrm{kHz} / \% \mathrm{RH}$ & 0.927 & $1 / 2$ & [19] \\
\hline s2DMoS ${ }^{2}$ & Resistive & $0-80$ & $85 \mathrm{~K} \Omega \% / \mathrm{RH}$ & 0.999 & $0.6 / 0.3$ & [61] \\
\hline Poly-AMPS/ TEOS & Resistive & $30-90$ & - & 0.998 & $<2 \min$ & [62] \\
\hline Organic silicon sol/poly-AMPS & Resistive & $30-90$ & - & 0.9491 & $30 / 60 \mathrm{~s}$ & [63] \\
\hline PEO-CuO-MWCNT: $1 \%$ & Resistive & $30-90$ & $3798.2 \%$ & 0.884 & $3 / 22 \mathrm{~s}$ & Current Study \\
\hline PEO-CuO-MWCNT: 3\% & Capacitive & $30-90$ & $53837.6 \%$ & 0.961 & $20 / 11 \mathrm{~s}$ & Current Study \\
\hline
\end{tabular}




\section{Conclusions}

A novel highly responsive humidity sensor was fabricated based on PEO-CuO-MWCNTs composite nanofibers. The composites nanofibers were developed for capacitive and resistive humidity applications prepared via electrospinning. The composite nanofibers PEO-CuO-MWCNT: $1 \%$ and PEO-CuO-MWCNT: $3 \%$ humidity sensor revealed high sensitivity with fast response and recovery time. We found that the PEO-CuO-MWCNT: $1 \%$ composite nanofibers showed high humidity sensitivity $(3798.2 \%)$ and exhibited a quick response of $3 \mathrm{~s}$ and recovery time of $22 \mathrm{~s}$. It was observed that in PEO-CuO-MWCNT: $1 \%$ composite nanofibers, the resistance increased linearly when exposed to humidity. The PEO-CuO-MWCNT: 3\% nanocomposite showed a response of 20s and a rapid recovery time of 11 s with high sensitivity $(53837,6 \%)$, while the capacitance increased as the frequency decreased. All results demonstrate that increasing the concentration of fillers i.e., $\mathrm{MWCNTs}$ and $\mathrm{CuO}$ nanoparticles is an effective approach to improve the sensing properties. The proposed method allows the scalable production of multicomponent sensor devices based on polymer matrix composite with high stability, flexibility and versatility for several industrial applications.

Supplementary Materials: The following are available online at https://www.mdpi.com/1996-1 944/14/4/1037/s1, Figure S1: The schematic diagram of the Electrospinning process; Figure S2: The XRD patterns of (a) pure PEO (b) CuO nanoparticles (c) MWCNT (d) PEO-CuO-MWCNT: $1 \%$ nanocomposite and (e) PEO-CuO-MWCNT: 3\% nanocomposite; Figure S3: EDS elemental profiles of (a) MWCNT (b) pure PEO (c) PEO-MWCNT-CuO: 1\% nanofibers, and (d) PEO-MWCNT-CuO: $3 \%$ composite nanofibers.

Author Contributions: W.A., B.J., original concept and initial draft of the paper; R.I., W.A., B.J., materials synthesis, adsorption and analysis of experiments; B.M.J., M.M.S., G.K., R.I., I.A., processing, structural characterizations and data analysis; M.M.S., B.M.J., I.A., supervised and coordinated the experimental work; G.K., R.I., funding acquisition. All authors have read and agreed to the published version of the manuscript.

Funding: This research was funded by Malaysia-Thailand Joint Authority under grant number IF0622019, Fundamental Research Grant Scheme FP050-2019A, and Kejuruteraan Kimia GPF078A2018 from University of Malaya. Moreover, this work was co-funded by the National Priorities Research Program grant No. NPRP11S-1128-170042 from the Qatar National Research Fund (member of The Qatar Foundation).

Institutional Review Board Statement: Not applicable.

Informed Consent Statement: Not applicable.

Data Availability Statement: All data reported here can be made available on request.

Conflicts of Interest: The authors declare no conflict of interest.

\section{References}

1. Shah, G.; Ullah, A.; Arshad, M.; Khan, R.; Ullah, B.; Ahmad, I. Resistive-and capacitive-type humidity and temperature sensors based on a novel caged nickel sulfide for environmental monitoring. J. Mater. Sci. Mater. Electron. 2020, 31, $3557-3563$.

2. Cai, B.; Yin, H.; Huo, T.; Ma, J.; Di, Z.; Li, M.; Hu, N.; Yang, Z.; Zhang, Y.; Su, Y. Semiconducting single-walled carbon nanotube/graphene van der Waals junctions for highly sensitive all-carbon hybrid humidity sensors. J. Mater. Chem. C 2020, 8, 3386-3394. [CrossRef]

3. Kundu, S.; Majumder, R.; Ghosh, R.; Pradhan, M.; Roy, S.; Singha, P.; Ghosh, D.; Banerjee, A.; Banerjee, D.; Chowdhury, M.P. Relative humidity sensing properties of doped polyaniline-encased multiwall carbon nanotubes: Wearable and flexible human respiration monitoring application. J. Mater. Sci. 2020, 55, 3884-3901. [CrossRef]

4. Chen, Z.; Lu, C. Humidity sensors: A review of materials and mechanisms. Sens. Lett. 2005, 3, 274-295. [CrossRef]

5. Sajid, M.; Kim, H.B.; Lim, J.H.; Choi, K.H. Liquid-assisted exfoliation of 2D hBN flakes and their dispersion in PEO to fabricate highly specific and stable linear humidity sensors. J. Mater. Chem. C 2018, 6, 1421-1432. [CrossRef]

6. Wang, Y.; Liu, Y.; Zou, F.; Jiang, C.; Mou, C.; Wang, T. Humidity sensor based on a long-period fiber grating coated with polymer composite film. Sensors 2019, 19, 2263. [CrossRef] 
7. Ahmadi Tabar, F.; Nikfarjam, A.; Tavakoli, N.; Nasrollah Gavgani, J.; Mahyari, M.; Hosseini, S.G. Chemical-resistant ammonia sensor based on polyaniline/CuO nanoparticles supported on three-dimensional nitrogen-doped graphene-based framework nanocomposites. Microchim. Acta 2020, 187, 1-13. [CrossRef]

8. Ze, L.; Yueqiu, G.; Xujun, L.; Yong, Z. MoS2-modified ZnO quantum dots nanocomposite: Synthesis and ultrafast humidity response. Appl. Surf. Sci. 2017, 399, 330-336. [CrossRef]

9. Ali, S.S.; Pauly, A.; Brunet, J.; Varenne, C.; Ndiaye, A.L. MWCNTs/PMMA/PS composites functionalized PANI: Electrical characterization and sensing performance for ammonia detection in a humid environment. Sens. Actuators B Chem. 2020, 128364.

10. Wang, X.; Ding, B.; Yu, J.; Wang, M. Highly sensitive humidity sensors based on electro-spinning/netting a polyamide 6 nano-fiber/net modified by polyethyleneimine. J. Mater. Chem. 2011, 21, 16231-16238. [CrossRef]

11. Konstantaki, M.; Papaioannou, G.; Pissadakis, S.; Pispas, S.; Madamopoulos, N.; Vainos, N. Optical fiber long-period grating humidity sensor utilizing PEO/ $\mathrm{CoCl}_{2}$ outcladding overlayers. In Optical Fibers: Application Proceedings of Congress of Optics and Optoelectronics, Warsaw, Poland, 28 August-2 September 2005; SPIE: Bellingham, WA, USA, 2015.

12. Wang, Y.; Shen, C.; Lou, W.; Shentu, F. Fiber optic humidity sensor based on the graphene oxide/PVA composite film. Opt. Commun. 2016, 372, 229-234. [CrossRef]

13. Vu, D.L.; Li, Y.-Y.; Lin, T.-H.; Wu, M.-C. Fabrication and humidity sensing property of UV/ozone treated PANI/PMMA electrospun fibers. J. Taiwan Inst. Chem. Eng. 2019, 99, 250-257. [CrossRef]

14. Singh, P.; Shukla, S. Structurally optimized cupric oxide/polyaniline nanocomposites for efficient humidity sensing. Surf. Interfaces 2020, 18, 100410. [CrossRef]

15. Megha, R.; Ravikiran, Y.; Chethan, B.; Prakash, H.R.; Kumari, S.V.; Thomas, S. Effect of mechanical mixing method of preparation of polyaniline-transition metal oxide composites on DC conductivity and humidity sensing response. J. Mater. Sci. Mater. Electron. 2018, 29, 7253-7261. [CrossRef]

16. Wang, S.-B.; Hsiao, C.-H.; Chang, S.-J.; Lam, K.-T.; Wen, K.-H.; Young, S.-J.; Hung, S.-C.; Huang, B.-R. CuO nanowire-based humidity sensor. IEEE Sens. J. 2011, 12, 1884-1888. [CrossRef]

17. Blank, T.A.; Eksperiandova, L.P.; Belikov, K.N. Recent trends of ceramic humidity sensors development: A review. Sens. Actuators B Chem. 2016, 228, 416-442. [CrossRef]

18. Silva, S.C.; Cardoso, R.M.; Richter, E.M.; Munoz, R.A.; Nossol, E. Reduced graphene oxide/multi-walled carbon nanotubes/prussian blue nanocomposites for amperometric detection of strong oxidants. Mater. Chem. Phys. 2020, 123011. [CrossRef]

19. Lin, Q.; Li, Y.; Yang, M. Highly sensitive and ultrafast response surface acoustic wave humidity sensor based on electrospun polyaniline/poly (vinyl butyral) nanofibers. Anal. Chim. Acta 2012, 748, 73-80. [CrossRef]

20. Mallick, S.; Ahmad, Z.; Touati, F.; Shakoor, R. Improvement of humidity sensing properties of PVDF-TiO 2 nanocomposite films using acetone etching. Sens. Actuators B Chem. 2019, 288, 408-413. [CrossRef]

21. Fratoddi, I.; Bearzotti, A.; Venditti, I.; Cametti, C.; Russo, M. Role of nanostructured polymers on the improvement of electrical response-based relative humidity sensors. Sens. Actuators B Chem. 2016, 225, 96-108. [CrossRef]

22. Sakai, Y.; Sadaoka, Y.; Matsuguchi, M. Humidity sensors based on polymer thin films. Sens. Actuators B Chem. 1996, 35, 85-90. [CrossRef]

23. Sakai, Y.; Sadaoka, Y.; Matsuguchi, M.; Sakai, H. Humidity sensor durable at high humidity using simultaneously crosslinked and quaternized poly (chloromethyl styrene). Sens. Actuators B Chem. 1995, 25, 689-691. [CrossRef]

24. Choi, S.; Lee, H.M.; Kim, H.S. Effect of molecular weight on humidity-sensitive characteristics of electrospun polyethylene oxide. Sens. Actuators A Phys. 2019, 294, 194-202. [CrossRef]

25. Zhang, D.; Tong, J.; Xia, B.; Xue, Q. Ultrahigh performance humidity sensor based on layer-by-layer self-assembly of graphene oxide/polyelectrolyte nanocomposite film. Sens. Actuators B Chem. 2014, 203, 263-270. [CrossRef]

26. Mazhar, S.; Qarni, A.A.; Haq, Y.U.; ul Haq, Z.; Murtaza, I.; Ahmad, N.; Jabeen, N.; Amin, S. Electrospun PVA/TiC Nanofibers for High Performance Capacitive Humidity Sensing. Microchem. J. 2020, 104974. [CrossRef]

27. Waber, T.; Sax, M.; Pahl, W.; Stufler, S.; Leidl, A.; Günther, M.; Feiertag, G. Fabrication and characterization of a piezoresistive humidity sensor with a stress-free package. J. Sens. Sens. Syst. 2014, 3, 167. [CrossRef]

28. Likhite, R.; Banerjee, A.; Majumder, A.; Karkhanis, M.; Kim, H.; Mastrangelo, C.H. Parametrically amplified low-power MEMS capacitive humidity sensor. Sensors 2019, 19, 3954. [CrossRef]

29. Reddy, S.; Swamy, B.K.; Jayadevappa, H. CuO nanoparticle sensor for the electrochemical determination of dopamine. Electrochim. Acta 2012, 61, 78-86. [CrossRef]

30. Lima, A.P.; Catto, A.C.; Longo, E.; Nossol, E.; Richter, E.M.; Munoz, R.A. Investigation on acid functionalization of double-walled carbon nanotubes of different lengths on the development of amperometric sensors. Electrochim. Acta 2019, 299, 762-771. [CrossRef]

31. Ardeshirzadeh, B.; Anaraki, N.A.; Irani, M.; Rad, L.R.; Shamshiri, S. Controlled release of doxorubicin from electrospun $\mathrm{PEO} /$ chitosan/graphene oxide nanocomposite nanofibrous scaffolds. Mater. Sci. Eng. 2015, 48, 384-390. [CrossRef]

32. Rajeh, A.; Morsi, M.; Elashmawi, I. Enhancement of spectroscopic, thermal, electrical and morphological properties of polyethylene oxide/carboxymethyl cellulose blends: Combined FT-IR/DFT. Vacuum 2019, 159, 430-440. [CrossRef]

33. Radhakrishnan, A.A.; Beena, B.B. Structural and optical absorption analysis of CuO nanoparticles. Indian J. Adv. Chem. Sci. 2014, 2, 158-161. 
34. Takassi, M.; Zadehnazari, A. Nanocomposites of triazole functionalized multi-walled carbon nanotube with chemically grafted polyimide: Preparation, characterization, and properties. Fuller 2016, 24, 128-138. [CrossRef]

35. Xianhua, C.; Khanmirzaei, M.H.; Omar, F.S.; Kasi, R.; Subramaniam, R.T. The effect of incorporation of multi-walled carbon nanotube into poly (ethylene oxide) gel electrolyte on the photovoltaic performance of dye-sensitized solar cell. Polym. -Plast. Technol. Mater. 2019, 58, 97-104. [CrossRef]

36. Phiwdang, K.; Suphankij, S.; Mekprasart, W.; Pecharapa, W. Synthesis of CuO nanoparticles by precipitation method using different precursors. Energy Procedia 2013, 34, 740-745. [CrossRef]

37. Li, F.; Gao, J.; Li, X.; Li, Y.; He, X.; Chen, L.; Zhang, Y. Preparation of magnetic molecularly imprinted polymers functionalized carbon nanotubes for highly selective removal of aristolochic acid. J. Chromatogr. A 2019, 1602, 168-177. [CrossRef]

38. Lin, Y.W.; Wu, T.M. Fabrication of water-soluble polyaniline/poly (ethylene oxide)/carbon nanotube electrospun fibers. J. Appl. Polym. Sci. 2012, 126, E123-E129. [CrossRef]

39. Banitaba, S.N.; Semnani, D.; Heydari-Soureshjani, E.; Rezaei, B.; Ensafi, A.A. Nanofibrous poly (ethylene oxide)-based structures incorporated with multi-walled carbon nanotube and graphene oxide as all-solid-state electrolytes for lithium ion batteries. Polym. Int. 2019, 68, 1787-1794. [CrossRef]

40. Prakash, L.; Tirupathi, C. Synthesis and Characterization of Pure and Rare-Earth Metal Gd Doped SnO 2-CuO Nanoparticles by Co-Precipitation Method. J. Nanosci. Technol. 2018, 478-482. [CrossRef]

41. Morsi, M.A.; Rajeh, A.; Al-Muntaser, A.A. Reinforcement of the optical, thermal and electrical properties of PEO based on MWCNTs/Au hybrid fillers: Nanodielectric materials for organoelectronic devices. Compos. Part B Eng. 2019, $173,106957$. [CrossRef]

42. Naghdi Sedeh, N.; Entezam, M.; Hassan Jafari, S.; Khonakdar, H.A.; Abdouss, M. Morphology, drug release behavior, thermal, and mechanical properties of poly (ethylene oxide)(PEO)/poly (vinyl pyrrolidone)(PVP) blends. J. Appl. Polym. Sci. 2018, 135, 46403. [CrossRef]

43. Mallakpour, S.; Mansourzadeh, S. Sonochemical synthesis of PVA/PVP blend nanocomposite containing modified CuO nanoparticles with vitamin B1 and their antibacterial activity against Staphylococcus aureus and Escherichia coli. Ultrason. Sonochemistry 2018, 43, 91-100. [CrossRef]

44. Phan, D.-T.; Park, I.; Park, A.-R.; Park, C.-M.; Jeon, K.-J. Black P/graphene hybrid: A fast response humidity sensor with good reversibility and stability. Sci. Rep. 2017, 7, 1-7.

45. Jiang, W.F.; Xiao, S.H.; Feng, C.Y.; Li, H.Y.; Li, X.J. Resistive humidity sensitivity of arrayed multi-wall carbon nanotube nests grown on arrayed nanoporous silicon pillars. Sens. Actuators B Chem. 2007, 125, 651-655. [CrossRef]

46. Wang, J.; Wan, H.; Lin, Q. Properties of a nanocrystalline barium titanate on silicon humidity sensor. Meas. Sci. Technol. 2003, 14, 172. [CrossRef]

47. Wang, Q.; Pan, Y.; Huang, S.; Ren, S.; Li, P.; Li, J. Resistive and capacitive response of nitrogen-doped $\mathrm{TiO}_{2}$ nanotubes film humidity sensor. Nanotechnology 2010, 22, 025501. [CrossRef]

48. Parangusan, H.; Bhadra, J.; Ahmad, Z.; Mallick, S.; Touati, F.; Al-Thani, N. Capacitive type humidity sensor based on PANI decorated $\mathrm{Cu}-\mathrm{ZnS}$ porous microspheres. Talanta 2020, 219, 121361. [CrossRef]

49. Wang, Z.; Shi, L.; Wu, F.; Yuan, S.; Zhao, Y.; Zhang, M. The sol-gel template synthesis of porous $\mathrm{TiO}_{2}$ for a high performance humidity sensor. Nanotechnology 2011, 22, 275502. [CrossRef]

50. Lee, J.; Cho, D.; Jeong, Y. A resistive-type sensor based on flexible multi-walled carbon nanotubes and polyacrylic acid composite films. Solid-State Electron. 2013, 87, 80-84. [CrossRef]

51. Kingston, C.; Zepp, R.; Andrady, A.; Boverhof, D.; Fehir, R.; Hawkins, D.; Roberts, J.; Sayre, P.; Shelton, B.; Sultan, Y.; et al. Release characteristics of selected carbon nanotube polymer composites. Carbon 2014, 68, 33-57. [CrossRef]

52. Singh, P.; Kushwaha, C.S.; Shukla, S.K.; Dubey, G.C. Synthesis and Humidity Sensing Properties of NiO Intercalated Polyaniline Nanocomposite. Polym. -Plast. Technol. Mater. 2019, 58, 139-147. [CrossRef]

53. Zhang, J.; Liu, X.; Neri, G.; Pinna, N. Nanostructured materials for room-temperature gas sensors. Adv. Mater. 2016, $28,795-831$. [CrossRef] [PubMed]

54. Kim, S.J.; Koh, H.-J.; Ren, C.E.; Kwon, O.; Maleski, K.; Cho, S.-Y.; Anasori, B.; Kim, C.-K.; Choi, Y.-K.; Kim, J. Metallic Ti3C2T x MXene gas sensors with ultrahigh signal-to-noise ratio. Acs Nano 2018, 12, 986-993. [CrossRef] [PubMed]

55. Aman Qazi, R.; Saleem Khan, M.; Siddiq, M.; Ullah, R.; Ali Shah, L.; Ali, M. Synthesis and characterization of functionalized MWCNTs/PMMA composites: Device fabrication for RH sensing. Polym. Plast. Technol. Mater. 2020, 1-13. [CrossRef]

56. Rahim, I.; Shah, M.; Wahab, F.; Iqbal, M. Comparative study of microstructural and humidity-sensing properties of graphenebased nanocomposite thin film. Meas. Sci. Technol. 2019, 31, 035104. [CrossRef]

57. Jeseentharani, V.; Jeyaraj, B.; Pragasam, J.; Dayalan, A.; Nagaraja, K.S. Humidity sensing properties of $\mathrm{CuO}, \mathrm{ZnO}$ and $\mathrm{NiO}$ composites. Sens. Transducers 2010, 113, 48.

58. Khanna, V.; Nahar, R. Surface conduction mechanisms and the electrical properties of Al2O3 humidity sensor. Appl. Surf. Sci. 1987, 28, 247-264. [CrossRef]

59. Li, X.; Chen, X.; Chen, X.; Ding, X.; Zhao, X. High-sensitive humidity sensor based on graphene oxide with evenly dispersed multiwalled carbon nanotubes. Mater. Chem. Phys. 2018, 207, 135-140. [CrossRef]

60. Sheng, L.; Dajing, C.; Yuquan, C. A surface acoustic wave humidity sensor with high sensitivity based on electrospun MWCNT/Nafion nanofiber films. Nanotechnology 2011, 22, 265504. [CrossRef] 
61. Yousaf, H.Z.; Kim, S.W.; Hassan, G.; Karimov, K.; Choi, K.H.; Sajid, M. Highly sensitive wide range linear integrated temperature compensated humidity sensors fabricated using Electrohydrodynamic printing and electrospray deposition. Sens. Actuators $B$ Chem. 2020, 308, 127680. [CrossRef]

62. Su, P.-G.; Chen, I.C.; Wu, R.-J. Use of poly (2-acrylamido-2-methylpropane sulfonate) modified with tetraethyl orthosilicate as sensing material for measurement of humidity. Anal. Chim. Acta 2001, 449, 103-109. [CrossRef]

63. Su, P.-G.; Uen, C.-L. A resistive-type humidity sensor using composite films prepared from poly (2-acrylamido-2-methylpropane sulfonate) and dispersed organic silicon sol. Talanta 2005, 66, 1247-1253. [CrossRef] 